\title{
Inhibitory Effect of Sulfur-containing Compounds on Anodic Oxidation of Borohydride
}

\section{Shoei MIZUHASHI, ${ }^{\mathrm{a}, \mathrm{b}, *}$ Christopher E. J. CORDONIER, ${ }^{\mathrm{a}}$ Yusuke SATO, ${ }^{\mathrm{b}}$ Hideo HONMA, ${ }^{a}$ and Osamu TAKAI ${ }^{\mathrm{a}}$}

\author{
a Materials \& Surface Engineering Research Institute, Kanto Gakuin University, \\ 1-1-1 Fukuura, Kanazawa, Yokohama 236-8501, Japan \\ ${ }^{b}$ Chemical Products Department, Precious Metal Material Division, Matsuda Sangyo Co., Ltd., \\ 60 Negishi, Iruma, Saitama 358-0034, Japan
}

*Corresponding author: mizuhashi-s@matsuda-sangyo.co.jp

\begin{abstract}
Inhibitory effect of sulfur-containing compounds on anodic oxidation of borohydride was investigated. The linear sweep voltammetry technique revealed that sulfur compounds such as thiosulfate and sulfide inhibited anodic oxidation of borohydride not only on a platinum surface but also on a glassy carbon surface which had less catalytic activity of borohydride electro-oxidation. Through electrochemical impedance spectroscopy, it was confirmed the charge transfer resistance of borohydride oxidation at the electrode surface increased in the presence of sulfur compounds, but the capacitance of the electric double layer at the surface did not depend on sulfur compounds and their concentration. The degree of inhibition by each sulfur compound on the electro-oxidation of borohydride in the presence of electrodes and its spontaneous oxidation in the absence of electrodes was similar. Thus the sulfur compound inhibitive influence on borohydride oxidation occurred without adsorbing onto the surface of the electrode. The anodic oxidation of borohydride was suppressed to less than 1/10 of the exchange current in the case of thiosulfate and sulfide. Sulfur compounds inhibited anodic oxidation of hydrazine and dimethylaminoborane as well, while the effect of each sulfur compound varied from that of borohydride.
\end{abstract}

(c) The Electrochemical Society of Japan, All rights reserved.

Keywords : Inhibitory Effect, Sulfur, Oxidation, Borohydride

\section{Introduction}

Sulfur compounds such as sulfide are widely known as "catalytic poison" reducing the catalytic activities of platinum, ${ }^{1}$ because of strong adsorption onto the active catalytic sites on the metals. For example, sulfur compounds (sulfide, thiol and disulfide) have been reported as poisons for all catalytic processes employing reduce metals as the primary active phase. ${ }^{2}$ Gaseous sulfur compounds, such as $\mathrm{SO}_{2}$, on platinum surfaces inhibit the catalytic activity of platinum. ${ }^{3,4}$ Sulfate and bisulfate adsorption on platinum surfaces was directly observed by in situ scanning tunneling microscopy technique..$^{5}$ Coverage of sulfur on a platinum electrode was estimated using cyclic voltammetry and surface science techniques such as low-energy electron diffraction. ${ }^{6}$ In addition, sulfur compounds such as thiourea have been studied as corrosion inhibitors for pure iron and stainless steels. ${ }^{7-10}$

Borohydride and its oxidation mechanism has been studied in relation to direct borohydride fuel cells (DBFC) ${ }^{11-15}$ In addition, this strong reducing agent is commonly utilized for chemical deposition of metal films. ${ }^{16}$ Although anodic oxidation inhibition of borohydride on platinum electrodes by sulfur compounds dissolved in the electrolytes has been reported, ${ }^{17}$ data regarding the inhibitory effect is not common. Furthermore, the inhibitory effect is generally interpreted as the result of adsorption of the sulfur compound on the catalytically active sites on the catalyst surface. However, the correlation between the inhibitory effect on electro oxidation on a platinum surface and the sulfur compound adsorption onto the electrode surface has not been thoroughly studied and discussed.

This paper reports the inhibitory effect of sulfur compounds (thioethers, thiols, disulfides, thiocarbonyls and sulfides) on anodic oxidation of borohydride investigated using linear sweep voltam- metry (LSV). In addition, electrochemical impedance spectroscopy (EIS) was used to clarify the relation between sulfur compound adsorption on the electrode surface and variation of charge transfer resistance derived from the sulfur compounds. The inhibitory effect of sulfur compounds on the spontaneous oxidation of borohydride was also investigated and the result compared with that of the electrochemical study. The inhibition mechanism of sulfur compounds may be of value in the fields of catalysts and plating.

\section{Experimental}

\subsection{The sulfur compounds investigated}

Sulfur compounds representative of thioethers; 2,2'-thiodiacetic acid (TDA) and DL-methionine (MTN), thiols; tiopronin (TPN), disulfides; bis- (sodium sulfopropyl) -disulfide (SPS), thiosulfates; sodium thiosulfate (TSL), thiocarbonyls; thiourea (TUR), and sulfides; sodium sulfide nonahydrate (SLF) were used in the experiments. The chemical structure of selected sulfur compounds are shown in Fig. 1.

\subsection{Linear sweep voltammetry}

The electrolyte was composed of $0.25 \mathrm{M} \mathrm{NaOH}, 0.1 \mathrm{M}$ sodium borohydride $(\mathrm{SBH})$, and $0.031 \mathrm{mM}$ sulfur compound $(\mathrm{M}=$ mol dm${ }^{-3}$ ). The $\mathrm{pH}$ in all experiments were in the range of 13.313.6 at $25^{\circ} \mathrm{C}$. The LSV measurements were performed using a three electrode setup on an IviumStat potentiostat (Ivium Technologies) with a bare platinum disk as the working electrode, a platinum wire as the counter electrode, and an $\mathrm{Ag} / \mathrm{AgCl}$ electrode as the reference electrode. In some cases, a glassy carbon (GC) electrode was used as the working electrode for comparison. The LSV measurements were carried out from open circuit and potential increased at a scan rate of $2 \mathrm{mV} \mathrm{s}^{-1}$, at $25^{\circ} \mathrm{C}$. Hydrazine and dimethylaminoborane (DMAB) 
<smiles>O=C(O)CSCC(=O)O</smiles>

2,2'-Thiodiacetic acid : TDA<smiles>[NH3+][OH+]S(=O)([OH2+])=S</smiles>

Sodium thiosulfate : TSL<smiles>CC(S)C(=O)NCC(=O)O</smiles>

Tiopronin : TPN

Figure 1. Chemical structures of the sulfur containing compounds.

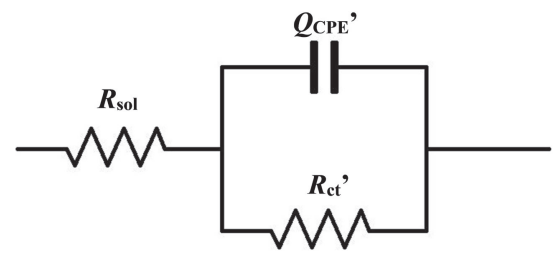

Figure 2. The equivalent circuit used to fit the EIS data. The $R_{\text {sol }}$ represents the solution resistance, and $R_{\mathrm{ct}}{ }^{\prime}$ represents the charge transfer resistance. The $Q_{\mathrm{CPE}}{ }^{\prime}$ is the constant phase element.

instead of SBH were also examined as reducers at the same concentration for comparison.

\subsection{Electrochemical impedance spectroscopy}

The same apparatus and platinum electrode described in 2.2 were used with a two electrode cell in which two platinum electrodes were used as the working electrodes. The impedance spectra were measured at $25^{\circ} \mathrm{C}$ in the frequency range from $10 \mathrm{mHz}$ to $10 \mathrm{kHz}$ at five frequencies per decade with an $\mathrm{AC}$ amplitude of $10 \mathrm{mV}$ at $0 \mathrm{~V}$ DC offset. The electrolyte contained $0.25 \mathrm{M} \mathrm{NaOH}$ as the supporting electrolyte, $0.013 \mathrm{M} \mathrm{SBH}$ and $0.031 \mathrm{mM}$ sulfur compound (TDA, TPN or TSL). For TSL, the effect of varying concentration was also investigated.

To fit the EIS data, a model which includes the constant-phase element $(\mathrm{CPE})$ were used. The $\mathrm{CPE}$ impedance $\left(Z_{\mathrm{CPE}}\right)$ expressed in terms of the model parameters $p$ and $Q_{\mathrm{CPE}}$ is as follows; ${ }^{18}$

$$
Z_{\mathrm{CPE}}=\frac{1}{(j \omega)^{p} Q_{\mathrm{CPE}}}
$$

Here, $j$ is the imaginary unit and $\omega$ is angular frequency. When $p=1$, the parameter $Q_{\mathrm{CPE}}$ has units of capacitance, otherwise, $Q_{\mathrm{CPE}}$ has units of $F s^{(p-1)}$. The equivalent circuit used in the investigation is shown in Fig. 2, where $R_{\text {sol }}$ represents the solution resistance and $R_{\mathrm{ct}}{ }^{\prime}$ represents the charge transfer resistance, respectively. The $Q_{\mathrm{CPE}}$ can be approximated as the capacitance of the electric double layer on the electrode surface. This equivalent circuit is commonly used in the field of corrosion science in order to evaluate corrosion rate of metals such as steel and adsorption of inhibitors onto the surface, ${ }^{10,19-22}$ and it is also suitable for evaluation of sulfur compounds inhibitors in this study.

\subsection{Inhibitory effect of the sulfur compounds on spontaneous oxidation of $\mathrm{SBH}$}

The solutions were composed of $0.25 \mathrm{M} \mathrm{NaOH}, 0.013 \mathrm{M} \mathrm{SBH}$ and $0.031 \mathrm{mM}$ sulfur compound (TDA, TPN, SLF or TSL). A solution without SBH and sulfur compound was also examined for comparison. Oxidation reduction potential (ORP) of the test

solutions stored in polypropylene bottles was measured at the specified intervals of time using an ORP combination electrode (TOA DKK, model PST-2739C). Measurements were conducted over a 100 day period.

\section{Results and Discussion}

\subsection{Inhibitory effect of sulfur compounds on anodic oxidation of $\mathrm{SBH}$}

The inhibitory effect of the sulfur compounds on anodic oxidation of SBH was investigated by measurement of the anodic polarization curves using LSV. Figure 3 shows the anodic polarization curves of the electrolytes containing sulfur compounds (TDA, TPN, TSL and SLF as representative examples) on the platinum and GC electrodes. MTN and TDA showed similar results, as did SPS and TPN, and TUR and SLF. On the platinum surface SBH was oxidized at a negative potential, therefore more easily, compared to on the GC electrode. This demonstrated the catalytic activity of platinum on the oxidation of SBH was higher than that of the GC electrode. Interestingly, TPN, TSL and SLF demonstrated an inhibitory effect not only on the platinum electrode but also on the GC electrode. Therefore, the inhibitory effect of sulfur compounds may not be directly related to the catalytic activity of the electrode surface.

It should be additionally noted that this inhibitory effect was not confirmed in the case of nitrogen compounds (3-amino pyridine, $2,2^{\prime}$-dipyridyl and $o$-phenanthroline) or poly ethylene glycol when examined under the same conditions, thus it can be said that this effect is quite unique to sulfur compounds.

\subsection{EIS study}

In order to clarify the influence of sulfur compounds on the charge transfer resistivity $\left(R_{\mathrm{ct}}\right)$ of the electrochemical reactions and the capacitance of electric double layer of the electrode surface, EIS was carried out. The Nyquist plot for variation of sulfur compounds is shown Fig. 4, and that for variation of TSL concentration is shown in Fig. 5. The estimated values of $R_{\mathrm{ct}}$ and $Q_{\mathrm{CPE}}$ by fitting the resulting curves are listed in Table 1 for variation of the sulfur compound, and shown in Fig. 6 for variation of the TSL concentration. These values were re-estimated according to the following relationship; $R_{\mathrm{ct}}=R_{\mathrm{ct}}{ }^{\prime} / 2$ and $Q_{\mathrm{CPE}}=2 \times Q_{\mathrm{CPE}^{\prime}}{ }^{\prime}$, because the values of $R_{\mathrm{ct}}$ and $Q_{\mathrm{CPE}}$ could be assumed to be the same when both electrodes in the measurement system were the same.

As shown in Table 1, the $R_{\mathrm{ct}}$ increased in the presence of a sulfur compound, and the more the sulfur compound inhibited the anodic oxidation of SBH as shown in Fig. 3, the higher the $R_{\mathrm{ct}}$ became. Thus, the $R_{\mathrm{ct}}$ corresponded to the charge transfer resistance of SBH anodic oxidation. On the other hand, a clear relation between sulfur compounds and $Q_{\mathrm{CPE}}$ was not confirmed. Likewise, the $R_{\mathrm{ct}}$ monotonically increased with increase of TSL concentration as shown in Fig. 6, while $Q_{\mathrm{CPE}}$ did not strongly depend on the TSL concentration. Especially, $Q_{\mathrm{CPE}}$ did not change between $0.031 \mathrm{mM}$ and $0.15 \mathrm{mM}$ while the $R_{\mathrm{ct}}$ drastically increased in this range. Generally, $Q_{\mathrm{CPE}}$ value decreases when chemical species such as inhibitors adsorb onto an electrode surface, because they displace the water molecules and other ions originally adsorbed on the surface ${ }^{21}$ and this replacement decreases the local dielectric constant of the electric double layer as the capacitance is given as follows: ${ }^{23,24}$

$$
C=\frac{\varepsilon_{0} \varepsilon}{d} A
$$

Where $C$ is the capacitance, $\varepsilon_{0}$ is the permittivity of air, $\varepsilon$ is the local dielectric constant, $d$ is the distance of the electrodes and $A$ is the surface area of electrode. Therefore, the result indicated the sulfur compounds such as TSL can inhibit the electrochemical reaction on the platinum surface without chemisorbing onto the surface of the platinum. 
(a) TDA

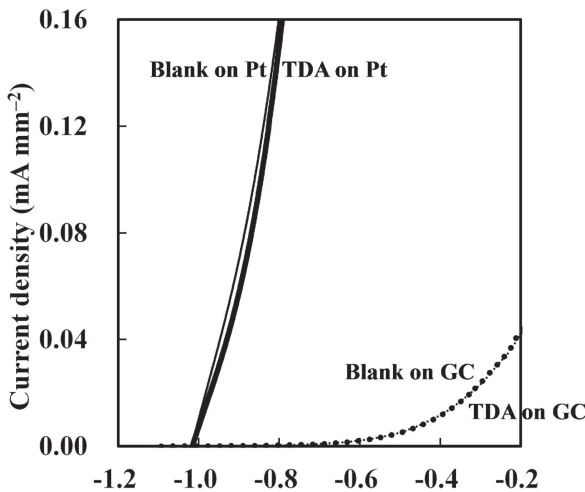

(c) TSL (b) TPN

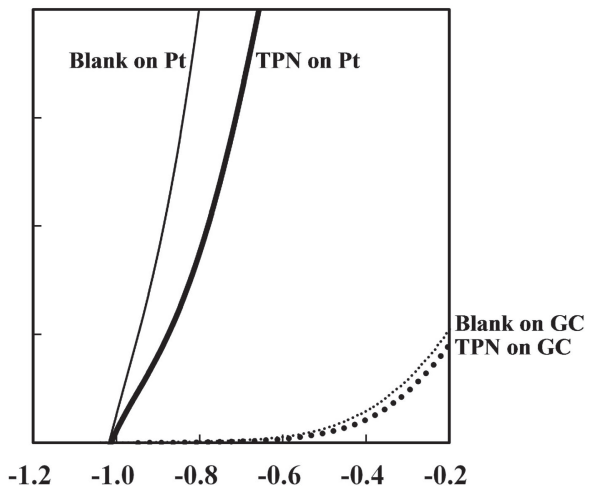

(d) SLF

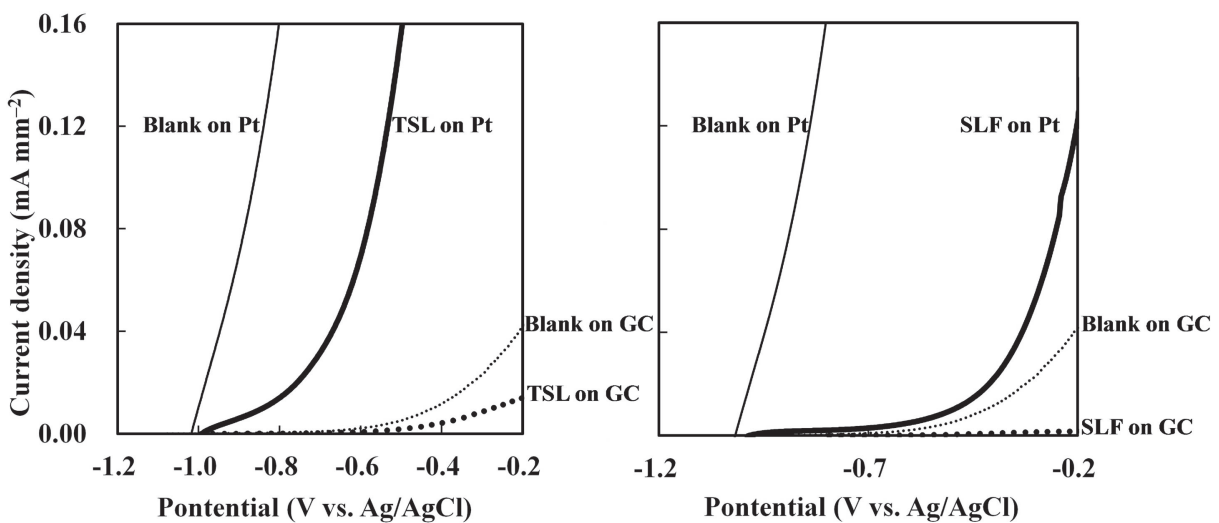

Figure 3. Anodic polarization curves of electrolytes containing SBH in the absence and presence of each sulfur compound ( $0.031 \mathrm{mM})$ on the platinum or GC electrode. The solid lines indicate the curves obtained using the platinum electrode, and the dotted lines those obtained on the GC electrode. The thin lines indicate the curves obtained from the electrolytes containing no sulfur compounds, and the bold lines those obtained from the electrolytes containing a sulfur compound.

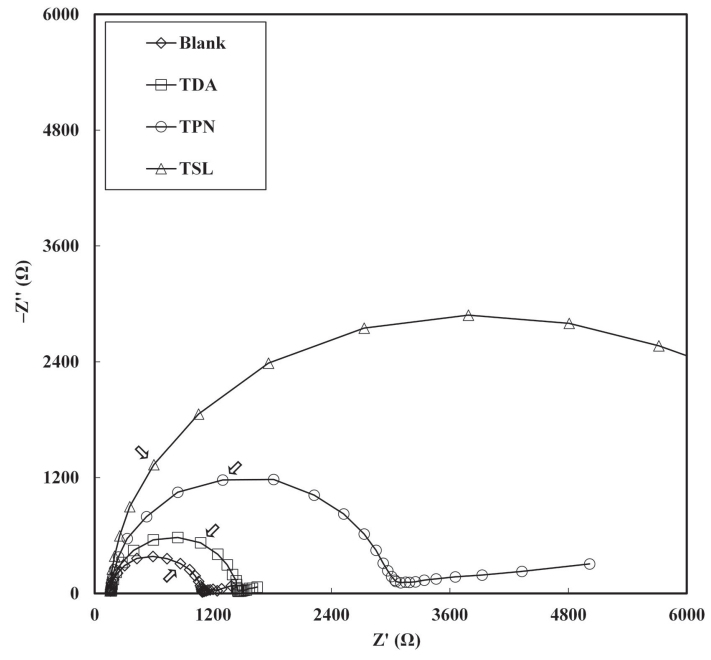

Figure 4. Nyquist plots of the electrolyte containing $\mathrm{SBH}$ and a sulfur compound at $0.031 \mathrm{mM}$. The arrows indicate the plots of frequency at $100 \mathrm{~Hz}$. The surface area of the electrodes was $2.0 \mathrm{~mm}^{2}$.

\subsection{Comparison with spontaneous SBH oxidation}

The inhibitory effect of the sulfur compounds on spontaneous oxidation of SBH was investigated for comparison. Figure 7 shows the ORP variation of the SBH solutions with varying sulfur compound as a function of elapsed time. Only the control solution

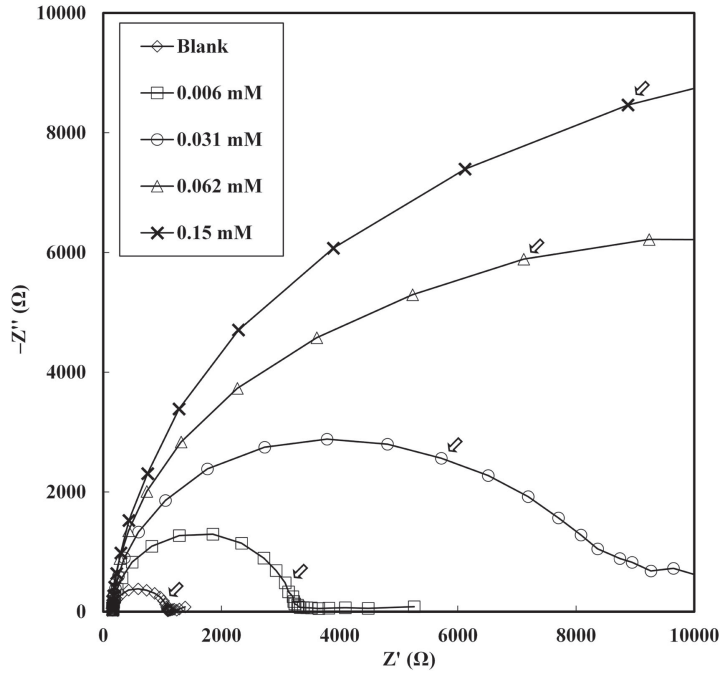

Figure 5. Nyquist plots of the electrolyte containing SBH and in the absence and presence of 0.006, 0.031, 0.062 and $0.15 \mathrm{mM}$ TSL. The arrows indicate the plots of frequency at $10 \mathrm{~Hz}$. The surface area of the electrodes was $2.0 \mathrm{~mm}^{2}$.

which did not contain SBH nor sulfur compound had a higher initial ORP than other solutions. When SBH in the test solutions is completely oxidized, ORP will increase up to that of the control solution. The ORP of the SBH solution that did not contain a sulfur 
Table 1. $R_{\mathrm{ct}}$ and $Q_{\mathrm{CPE}}$ values estimated by fitting the measurement result to the equivalent circuit. The electrolyte was examined in the absence and presence of $0.031 \mathrm{mM}$ of each sulfur compound. The surface area of the electrodes was $2.0 \mathrm{~mm}^{2}$.

\begin{tabular}{cccc}
\hline Sulfur compound & $\begin{array}{c}R_{\mathrm{ct}} \\
(\Omega)\end{array}$ & $\begin{array}{c}Q_{\mathrm{CPE}} \\
\left(\times 10^{-7} \mathrm{~F} \mathrm{~s}^{(p-1)}\right)\end{array}$ & $p$ \\
\hline None (blank) & 470 & 6.48 & 0.889 \\
TDA & 651 & 8.84 & 0.936 \\
TPN & 1433 & 5.67 & 0.893 \\
TSL & 3704 & 4.02 & 0.856 \\
\hline
\end{tabular}

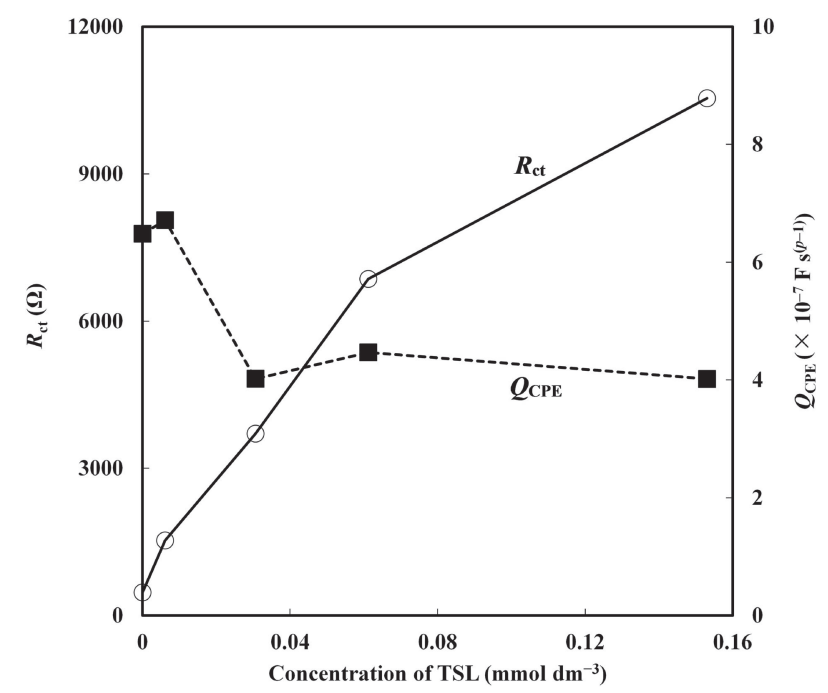

Figure 6. The $R_{\mathrm{ct}}$ and $Q_{\mathrm{CPE}}$ variations as a function of TSL concentration estimated by fitting the EIS results. The unit of $Q_{\mathrm{CPE}}$ is given in $\mathrm{F} \mathrm{s}^{(p-1)}$, where $p$ was also determined by fitting the data into the equivalent circuit. The surface area of the electrodes was $2.0 \mathrm{~mm}^{2}$.

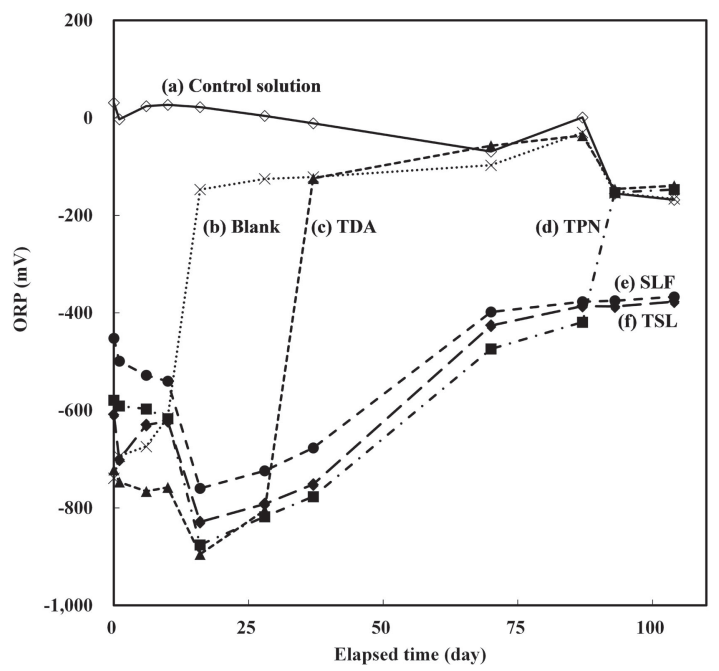

Figure 7. The ORP values of the test solutions as a function of elapsed time; (a) Control solution, (b) Blank, (c) TDA, (d) TPN, (e) TSL and (f) SLF. The test solutions from (c) to (f) contained each sulfur compound at $0.031 \mathrm{mM}$.

compound drastically increased about fifteen days after preparation due to spontaneous borohydride oxidation. On the other hand, the SBH solutions that included a sulfur compound maintained an ORP of less than $-500 \mathrm{mV}$ for 25 days or longer. The reason why ORP decreased during the first 16 days for TDA, TPN, TSL and SLF is not clearly understood at present. The ORP of the TDA solution increased to the same value as that of the control solution about 30 days after preparation. After 30 days or more, ORP of the TPN, TSL and SLF solutions began to gradually increase. A drastic increase in ORP occurred 90 days after preparation of the TPN solution. For the TSL and SLF solutions, ORP remained $200 \mathrm{mV}$ lower than that of the control solution. This slower and gradual increase of ORP in the presence of sulfur compounds demonstrated that they had an inhibitory effect not only on anodic oxidation but also on spontaneous oxidation of SBH. Furthermore, the degree of inhibitory effect of the sulfur compounds was similar to that of the anodic oxidation in the LSV measurements; TDA had almost no inhibitory effect, TPN had slight effect and TSL and SLF had great effect. This similarity may imply SBH electro-oxidation near the electrode surface and spontaneous SBH oxidation are inhibited by sulfur compounds through the same mechanism.

Complete oxidation of SBH is an eight-electron reaction as follows: $:^{25,26}$

$$
\mathrm{BH}_{4}{ }^{-}+8 \mathrm{OH}^{-} \rightarrow \mathrm{BO}_{2}^{-}+6 \mathrm{H}_{2} \mathrm{O}+8 \mathrm{e}^{-}
$$

A competitive side reaction occurs as follow: ${ }^{26}$

$$
\mathrm{BH}_{4}{ }^{-}+2 \mathrm{H}_{2} \mathrm{O} \rightarrow \mathrm{BO}_{2}{ }^{-}+4 \mathrm{H}_{2}
$$

In this measurement, dissolved oxygen was reduced by the first oxidation of SBH shown above. Sulfur compounds have been widely known as an antioxidant due to its scavenging ability of reactive oxygen species. ${ }^{27,28}$ The oxidation process of $\mathrm{SBH}$ also includes generation of radicals. ${ }^{25}$ Sulfur compounds may be able to directly inhibit the radical reactions without adsorbing onto the surface of the electrode. When SBH is oxidized on the surface of a platinum electrode, sulfur compounds may scavenge active radical species of borohydride.

\subsection{Influence of concentration and the differences between other reducers}

The impact of sulfur compounds concentration on anodic polarization curves was shown in Fig. 8 in which potential is given in overpotential (the difference between the open circuit potential and applied potential) and current is expressed with a logarithmic scale. TDA showed almost no inhibitory effect on SBH oxidation even when the concentration increased up to $0.39 \mathrm{mM}$. On the other hand, TPN, TSL and SLF demonstrated greater inhibition on SBH oxidation as the concentration increased. In addition, some anodic polarization curves were turbulent at higher overpotential. In the case of TPN and SLF, this was probably because hydrogen gas emitted from SBH oxidation covered the surface of the platinum electrode.

For a sufficiently large overpotential, the current density derived from the Butler-Volmer equation can be approximated by the Tafel plot, $\ln |i|$ vs. $\eta .^{29}$

$$
\eta=\frac{R T}{\alpha F} \ln i_{0}-\frac{R T}{\alpha F} \ln i
$$

Here, $\eta$ is the overpotential, $R$ is the gas constant, $T$ is the temperature, $F$ is Faraday's constant, $\alpha$ is the transfer coefficient and $i$ is the current (generally, current density) and $i_{0}$ is the exchange current. In addition, $i_{0}$ represents the current of an electrochemical reaction when oxidation and reduction occurs at the same rate and it represents the intrinsic rate of an electrochemical reaction. The impact of sulfur compound concentration $\left(C_{\mathrm{S}}\right)$ on $i_{0}$ estimated from the Tafel plots in a range of $0.05<\eta<0.2 \mathrm{~V}$ was shown in Fig. 9 (the maximum range of potential was limited at less than $0.2 \mathrm{~V}$ because the shape of polarization curve did not maintain the logarithmic function at $\eta=0.2 \mathrm{~V}$ or more for TPN, TSL and SLF). As for all the compounds including TDA for which the inhibitory effect on the anodic polarization curve did not clearly appear in 
(a) TDA

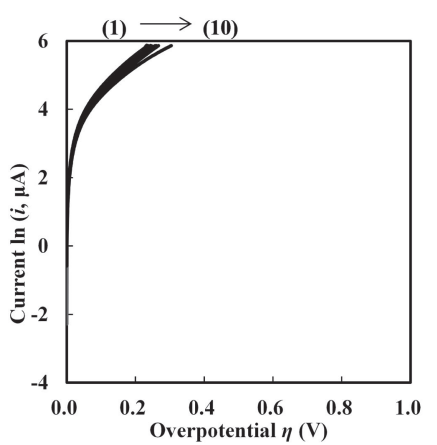

(c) TSL

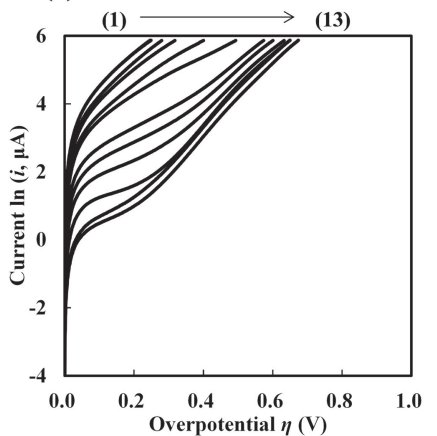

(b) TPN

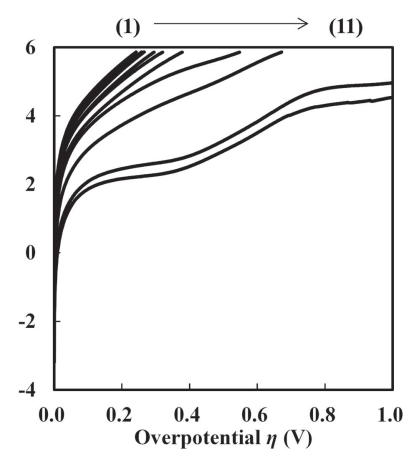

(d) SLF

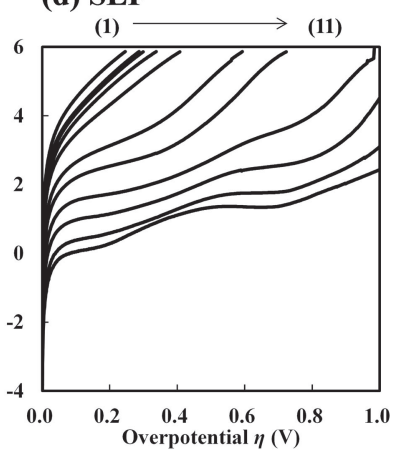

Figure 8. Anodic polarization curves of electrolyte containing SBH and each sulfur compound at various concentration; (a) TDA, (b) TPN, (c) TSL and (d) SLF, respectively. The horizontal arrows indicate the shift of curves by increasing sulfur compounds concentration; (1) no additive, (2) $0.00062 \mathrm{mM}$, (3) $0.0012 \mathrm{mM}$, (4) $0.0031 \mathrm{mM}$, (5) $0.0062 \mathrm{mM}$, (6) $0.015 \mathrm{mM}$, (7) $0.031 \mathrm{mM}$, (8) $0.077 \mathrm{mM}$, (9) $0.15 \mathrm{mM}$, (10) $0.39 \mathrm{mM}$, (11) $0.77 \mathrm{mM}$, (12) $1.9 \mathrm{mM}$, and (13) $3.9 \mathrm{mM}$, respectively. The surface area of the electrode was $2.0 \mathrm{~mm}^{2}$.

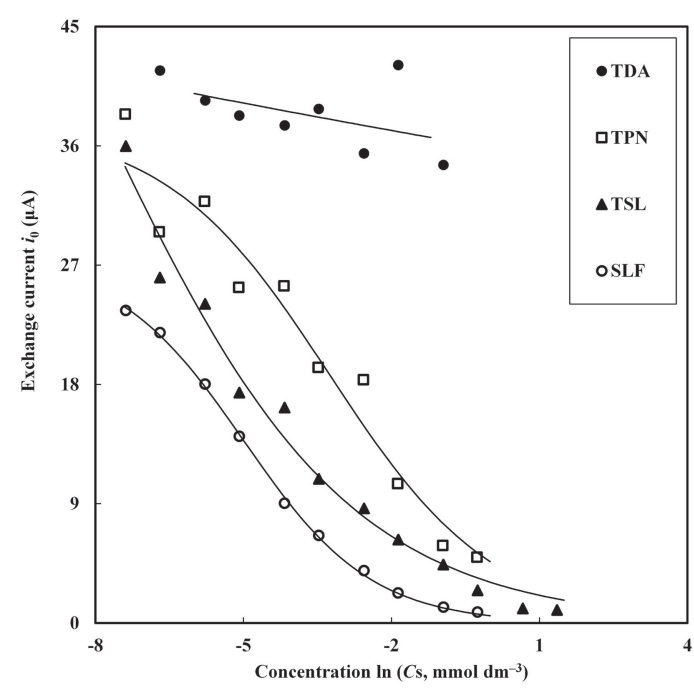

Figure 9. Exchange current estimated from Tafel plots of each electrolyte as a function of concentration of each sulfur compound $\left(C_{\mathrm{s}}\right)$. The surface area of the electrode was $2.0 \mathrm{~mm}^{2}$.

Fig. 8 , it was confirmed $i_{0}$ almost monotonically decreased as the concentration increased. Especially, the $i_{0}$ of TSL and SLF decreased to $1 / 10$ or less of the initial value measured in the absence of sulfur compounds for $\ln \left(C_{\mathrm{s}}\right)>-1$ or greater. It can be predicted that $i_{0}$ seemed to converge to 0 in the presence of sulfur compounds at high concentration.

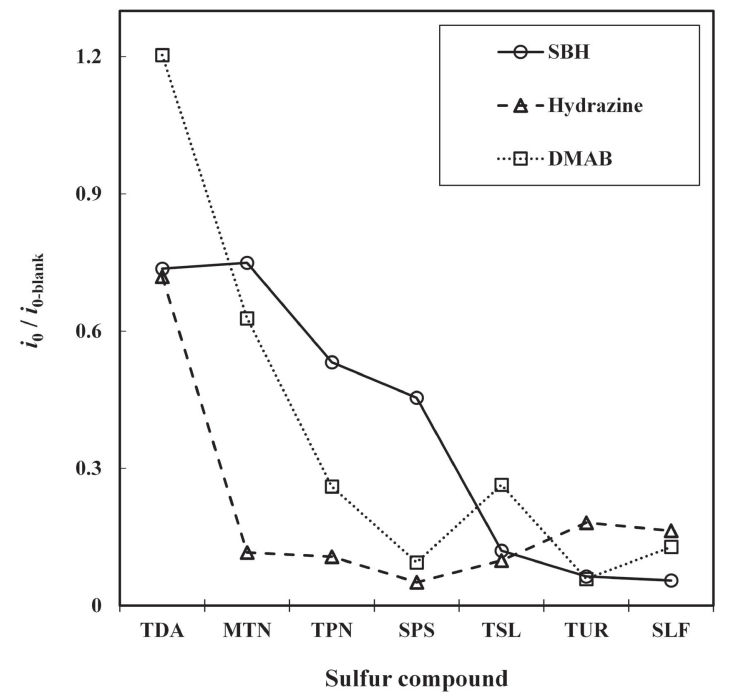

Figure 10. The relative ratio of the exchange current estimated based on the Tafel plots obtained from the electrolyte containing each reducers $(0.1 \mathrm{M})$ and sulfur compound $(0.031 \mathrm{mM})$. The denominator $i_{0-\text { blnak }}$ was the $i_{0}$ estimated from the electrolyte containing no sulfur compounds.

Variations of exchange current $i_{0}$ inhibited by sulfur compounds were also investigated for hydrazine and DMAB. Figure 10 shows the results as the relative ratio; $i_{0} / i_{0-\text { blank }}$, here $i_{0}$ is the estimated exchange current inhibited by sulfur compounds and $i_{0-\text { blank }}$ is that of blank electrolytes containing only each reducer. The inhibitory effect of the sulfur compounds depended on reducer. For example, hydrazine was greatly inhibited by all the sulfur compounds except for TDA, on the other hand TUR inhibited the anodic oxidation of $\mathrm{SBH}$ and DMAB more than hydrazine. This result indicated the sulfur compounds function as inhibitors not only through catalyst surface-sulfur interaction but also through sulfur-reducer direct interaction.

\section{Conclusions}

The inhibitory effect of sulfur compounds on anodic oxidation of borohydride was investigated by LSV technique under various conditions. Sulfur compounds such as TSL, TUR and SLF inhibited anodic oxidation of SBH not only on the platinum surface but also on the GC electrode surface which had less catalytic activity than the platinum electrode. The inhibition by sulfur compounds did not depend on catalytic activity of the surface.

The EIS measurement revealed that the resistance of charge transfer increased in the presence of sulfur compounds, while the capacitance of the electric double layer did not clearly change. In addition, the charge transfer resistance linearly increased with increasing sulfur compound (TSL) concentration. On the other hand, a clear relation between the capacitance of the electric double layer and TSL concentration was not confirmed. This suggested that the sulfur compounds inhibited SBH oxidation at the electrode even without adsorbing onto the surface.

Sulfur compounds also inhibited spontaneous oxidation of SBH in the absence of a platinum electrode, and the degree of inhibitory effect of sulfur compounds was similar to that observed in the LSV measurement.

With this inhibitory effect of sulfur compounds, the exchange current of anodic reaction was suppressed to less than $1 / 10$ of its original exchange current in the case of TSL and SLF. Sulfur compounds inhibited anodic oxidation of hydrazine and DMAB in addition to SBH, while the effect of each sulfur compound varied among these reducers. 


\section{Acknowledgment}

This work was supported in part by a MEXT-founded program for the Strategic Research Foundation at Private Universities.

\section{References}

1. G. A. Somorjai, J. Catal., 27, 453 (1972).

2. J. Dunleavy, Platin. Met. Rev., 50, 110 (2006)

3. T. E. Fischer and S. R. Kelemen, J. Catal., 53, 24 (1978)

4. J. C. Summers and K. Baron, J. Catal., 57, 380 (1979).

5. K. Itaya, Prog. Surf. Sci., 58, 121 (1998).

6. Y. E. Sung, W. Chrzanowski, A. Wieckowski, A. Zolfaghari, S. Blais, and G. Jerkiewicz, Electrochim. Acta, 44, 1019 (1998).

7. S. N. Raicheva, B. V. Aleksiev, and E. I. Sokolova, Corros. Sci., 34, 343 (1993).

8. X. L. Cheng, H. Y. Ma, S. H. Chen, R. Yu, X. Chen, and Z. M. Yao, Corros. Sci., 41, 321 (1998)

9. M. Özcan, Í. Dehri, and M. Erbil, Appl. Surf. Sci., 236, 155 (2004).

10. C. B. Shen, S. G. Wang, H. Y. Yang, K. Long, and F. H. Wang, Corros. Sci., 48 1655 (2006).

11. B. H. Liu, Z. P. Li, K. Arai, and S. Suda, Electrochim. Acta, 50, 3719 (2005).

12. R. X. Feng, H. Dong, Y. D. Wang, X. P. Ai, Y. L. Cao, and H. X. Yang, Electrochem. Commun., 7, 449 (2005)
13. N. A. Choudhury, R. K. Raman, S. Sampath, and A. K. Shukla, J. Power Sources, 143, 1 (2005).

14. M. H. Atwan, C. L. B. Macdonald, D. O. Northwood, and E. L. Gyenge, J. Power Sources, 158, 36 (2006)

15. E. Gyenge, M. Atwan, and D. Northwood, J. Electrochem. Soc., 153, A150 (2006).

16. T. S. N. S. Narayanan and S. K. Seshadri, J. Alloys Compd., 365, 197 (2004).

17. S. Mizuhashi, C. E. J. Cordonier, H. Honma, and O. Takai, J. Electrochem. Soc., 162, D497 (2015).

18. B. Hirschorn, M. E. Orazem, B. Tribollet, V. Vivier, I. Frateur, and M. Musiani, J. Electrochem. Soc., 157, C452 (2010).

19. M. Lebrini, M. Lagrenée, H. Vezin, M. Traisnel, and F. Bentiss, Corros. Sci., 49, 2254 (2007).

20. A. K. Singh and M. A. Quraishi, Corros. Sci., 52, 152 (2010).

21. M. Behpour, S. M. Ghoreishi, N. Mohammadi, N. Soltani, and M. SalavatiNiasari, Corros. Sci., 52, 4046 (2010)

22. X. Li, S. Deng, and H. Fu, Corros. Sci., 62, 163 (2012).

23. X. Li, S. Deng, and H. Fu, Corros. Sci., 53, 664 (2011).

24. Z. Cong, W. Li, D. Hu, Z. Lan, and B. Hou, Electrochemistry, 83, 262 (2015).

25. J. E. A. M. Van Den Meerakker, J. Appl. Electrochem., 11, 395 (1981).

26. B. H. Liu, Z. P. Li, and S. Suda, Electrochim. Acta, 49, 3097 (2004).

27. E. E. Battin and J. L. Brumaghim, Cell Biochem. Biophys., 55, 1 (2009).

28. E. Mukwevho, Z. Ferreira, and A. Ayeleso, Molecules, 19, 19376 (2014).

29. A. J. Bard and L. R. Faulkner, Electrochemical Methods Second Edition, John Wiley \& Sons, New York, p. 101 (2001). 